\title{
Clinical characteristics and risk factors for gout flare during the postsurgical period
}

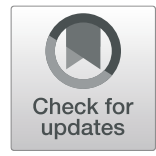

Hyemin Jeong and Chan Hong Jeon ${ }^{*}$

\begin{abstract}
Objectives: To evaluate the clinical features and risk factors for gout flare during postsurgical period in patients who were previously diagnosed with gout.

Methods: Seventy patients who had histories of gout and had been consulted in the rheumatologic clinic before surgery under general anesthesia were included. Clinical characteristics of patients who developed a postsurgical gout flare were compared with those of patients who did not develop gout flare.

Results: Among 70 patients, 31 (44.3\%) developed gout flare during the postsurgical period. Mean intervals from surgery to gout flare was 3.7 days. Flares tended to involve monoarticular joints (61.3\%) and affect lower extremity joints (83.9\%). Knee joints (26\%) and foot joints except the first metatarsophalangeal (MTP) joint (26\%) were more frequently involved than the first MTP joint (13\%). Presurgical uric acid level $\geq 9$ mg/dL (OR 3.77, 95\% Cl 1.28-11.10, $p=0.016)$ and amount of uric acid changes between before and after surgery (OR 1.62,95\% Cl 1.21-2.18, $p=0.001)$ were risk factors for postsurgical gout flare. Taking allopurinol reduced the risk of postsurgical gout flare (OR 0.15 , $95 \% \mathrm{Cl} 0.05-0.45, p=0.001$ ). Operation time, amount of blood loss during surgery, and surgery site were not significantly associated with postsurgical gout flare.
\end{abstract}

Conclusions: Adequate uric acid control before surgery could prevent the postsurgical gout flare.

Keywords: Gout, Surgery, Uric acid

\section{Introduction}

Gout is the most common inflammatory arthritis, affecting $3.9 \%$ of US adults, and the prevalence of gout is increasing over time [1, 2]. Hyperuricemia is a predisposing factor for gout, caused by formation of urate crystals. Monosodium urate (MSU) crystal is pathogenic crystals in gout (chemical formula $\mathrm{C}_{5} \mathrm{H}_{4} \mathrm{~N}_{4} \mathrm{NaO}_{3}$ ) [3]. Inflammatory response initiated by MSU crystal deposition in the joints, bones, and soft tissues. Releasing of MSU crystals from deposits is characteristic of gout flare [3]. Crystal activates NOD-like receptor protein 3 (NLRP3) inflammasome, which activates caspase- 1 and releases key cytokine interleukin (IL)-1 $\beta$ [4]. Histologic features of gout flare were synovial cell hyperplasia and infiltration of neutrophil, monocytes, and lymphocytes [5]. Interleukin-6, IL-8, and tumor necrosis factor (TNF) released by the synoviocytes and monocytes contributes to the joint inflammation during a gout flare [6-8].

\footnotetext{
* Correspondence: chjeon@gmail.com

Division of Rheumatology, Department of Internal Medicine, Soonchunhyang University Hospital, 170 Jomaru-ro, Wonmi-gu, Bucheon City, Gyenggi-do 14584 , South Korea
}

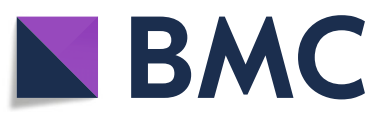

(c) The Author(s). 2019 Open Access This article is distributed under the terms of the Creative Commons Attribution 4.0 International License (http://creativecommons.org/licenses/by/4.0/), which permits unrestricted use, distribution, and reproduction in any medium, provided you give appropriate credit to the original author(s) and the source, provide a link to the Creative Commons license, and indicate if changes were made. The Creative Commons Public Domain Dedication waiver (http://creativecommons.org/publicdomain/zero/1.0/) applies to the data made available in this article, unless otherwise stated.
There are several risk factors for gout flare, including a meat- and seafood-rich diet, alcohol, sodas, fruit juice with high fructose or sucrose content, medications, such as diuretics or low-dose aspirin, menopause, and chronic kidney disease [9]. In addition, gout flares occur frequently in the postsurgical period. A previous study showed that $17.2 \%$ (52/302) of patients with a history of gout developed a gout flare during the postsurgical period. Another study reported that $33.3 \%(7 / 21)$ of patients with a previous history of gout developed an acute gout flare postoperatively after laparoscopic bypass [10]. Starvation, volume depletion, and tissue hypoxia are suspected precipitating factor for gout flare associated with surgery [11, 12]. Early detection and management of a gout flare are important, in order to reduce unnecessary antibiotics use or surgery and reduce days of hospitalization by enabling early ambulation. Studies about risk factors for postsurgical gout flare are relatively few. An association between gout flare and surgical factors, such as operation time or fluid intake during surgery, has rarely been reported. This study was intended to 
evaluate clinical characteristics and risk factors of gout flare during the postsurgical period.

\section{Method \\ Study population}

Subjects were selected from a pool of patients who had histories of gout and had been consulted in the rheumatologic clinic before surgery at a single tertiary hospital in South Korea between January 2007 and September 2017. A diagnosis of gout flare was made clinically by rheumatologists. A total of 184 patients were identified. Among them, surgery under local anesthesia and surgery for formation of arteriovenous fistulae for hemodialysis were excluded from the analysis. Patients with insufficient clinical information in the electronic medical record were excluded from the analysis. A total of 70 patients were included.

\section{Parameters collected}

Body mass index (BMI), medical comorbidities, including hypertension, diabetes mellitus, chronic kidney disease, dialysis, cardiovascular disease, and urinary stone, were collected through electronic medical record system. Information about joints involved in the gout flare, onset time were collected from the consultation sheet of the rheumatology department. Medications, including allopurinol, febuxostat, and colchicine were also collected. Any gout medications means taking one or more of the medications among allopurinol, febuxostat, and colchicine. Surgical factors, including surgical site, operation time, amount of blood loss, amount of fluid administration, and transfusion during the surgery, were collected through medical records. Uric acid levels at the pre- and postoperational period were identified, and the amount of uric acid changes between the pre- and post-operational periods was calculated.

\section{Statistical analysis}

Descriptive statistics were used to identify the characteristics of the study population. The clinical comparisons were performed using chi-square and Fisher exact tests for categorical variables and a student $t$-test for continuous variables. Correlations between uric acid changes and surgical factors, including total amount of fluids administered, were assessed using Pearson's correlation coefficient. Univariant logistic regression was used to analyze the risk factor of gout flare. All analyses were performed using SPSS version 19.0 (IBM Co., Armonk, NY, USA). MedCalc version 18.6 was used to calculate a receiver operating characteristics (ROC) curve and to analyze the specificity, sensitivity, and negative and positive predictive values of presurgical uric acid for the postsurgical gout flare. Statistical significance was assigned for $p<0.05$.

\section{Results}

Clinical characteristics of the 70 patients are shown in Table 1. Mean age was 62.6 years, and $60(85.7 \%)$ patients were male. Among the 70 patients, 31 (44.3\%) developed a gout flare during the postsurgical period. Preoperative uric acid levels were significantly higher in the flare group than in the no-flare group. The amount of uric acid change from before to after surgery was significantly higher in the flare group than in the no-flare group. The rate of allopurinol use was significantly lower in the flare group. Disease duration and comorbidities were not significantly different between the two groups.

Clinical characteristics of patients with a gout flare during the postsurgical period are shown in Table 2 . Mean intervals from surgery to gout flare was 3.7 days. Flares tended to be monoarticular and involved lower extremity joints more frequently. Among the 46 involved joints, including polyarticular joint flare, knee joints (26\%) and foot joints except the first metatarsophalangeal joint (MTP) (26\%) were more frequently involved than was the first MTP joint (13\%).

Surgical factors associated with gout flare are shown in Table 3. Operation time, amount of blood loss, fluid intake, and transfusion were not significantly different between the groups. Although there was no significant difference in surgical site between groups, the gastrointestinal tract was the most common surgical site in the flare group followed by the urinary tract. The amount of uric acid changes from before to after surgery was positively associated with the amount of fluid administered during surgery $(r=0.258, p=0.031)$. Blood loss, operation time, and amount of fluid according to the type were not significantly associated with the amount of uric acid changes.

High presurgical uric acid levels and a large change in the levels increased the risk of postsurgical gout flare (Table 4). Presurgical uric acid levels of $\geq 9 \mathrm{mg} / \mathrm{dL}$ were a significant risk factor for postsurgical gout flare. Taking any gout medications and allopurinol before surgery reduced the risk of gout flare. In the ROC analysis, a cutoff value for a presurgical uric acid level of more than $9.2 \mathrm{mg} / \mathrm{dL}$ had $41.9 \%$ sensitivity, $92.3 \%$ specificity, $81.3 \%$ positive predictive value, and $66.7 \%$ negative predictive value for postsurgical gout flare. The area under the curve (AUC) was found to be 0.70 (95\% CI $0.58-0.81$, $p=0.001$ ) for a cut-off value of $9.2 \mathrm{mg} / \mathrm{dL}$ (Fig. 1).

\section{Discussion}

We investigated the clinical characteristics of postsurgical gout flare. We found that the lower extremity joints were involved more often than upper extremity joint. Knee joints and foot joints except the first MTP joint were more frequently involved than was the first MTP joint. It is similar to a previous study which reported 
Table 1 Comparison of characteristics between patients with gout flare and without gout flare

\begin{tabular}{|c|c|c|c|c|}
\hline & All $(n=70)$ & Flare $(n=31)$ & No flare $(n=39)$ & $P$ value \\
\hline Age, years & $62.6 \pm 14.8$ & $64.1 \pm 16.2$ & $61.4 \pm 13.7$ & 0.463 \\
\hline Male & $60(85.7)$ & $28(90.3)$ & $32(82.1)$ & 0.495 \\
\hline $\mathrm{BMI}, \mathrm{kg} / \mathrm{m}^{2}$ & $25.0 \pm 4.3$ & $24.6 \pm 4.5$ & $25.3 \pm 4.2$ & 0.499 \\
\hline Disease duration, months & $54.3 \pm 48.4$ & $54.0 \pm 54.6$ & $54.6 \pm 43.8$ & 0.964 \\
\hline \multicolumn{5}{|l|}{ Comorbidities } \\
\hline Hypertension & $43(61.4)$ & $17(54.8)$ & $26(66.7)$ & 0.313 \\
\hline Diabetes Mellitus & $14(20.0)$ & $7(22.6)$ & $7(18.4)$ & 0.669 \\
\hline Chronic kidney disease & $37(52.9)$ & $14(45.2)$ & $23(59)$ & 0.250 \\
\hline Dialysis & $15(21.4)$ & 7 (22.6) & $8(20.5)$ & 0.834 \\
\hline Cardiovascular disease & $6(8.6)$ & $3(9.7)$ & $3(7.7)$ & 1.000 \\
\hline Urinary stone & $6(8.6)$ & $4(12.9)$ & $2(5.1)$ & 0.395 \\
\hline Presurgical uric acid, mg/dL & $7.8 \pm 2.3$ & $8.8 \pm 2.4$ & $7.1 \pm 1.9$ & 0.001 \\
\hline Postsurgical uric acid, mg/dL & $6.5 \pm 2.0$ & $6.2 \pm 2.3$ & $6.7 \pm 1.7$ & 0.281 \\
\hline Amount of uric acid change & $1.9 \pm 2.1$ & $2.8 \pm 2.4$ & $1.2 \pm 1.4$ & 0.001 \\
\hline \multicolumn{5}{|l|}{ Medication } \\
\hline Any gout medications ${ }^{a}$ & $40(57.1)$ & $9(29.0)$ & $31(79.5)$ & $<0.001$ \\
\hline Allopurinol & $30(42.9)$ & $6(19.4)$ & $24(61.5)$ & $<0.001$ \\
\hline Febuxostat & $6(8.6)$ & $1(3.2)$ & $5(12.8)$ & 0.161 \\
\hline Colchicine & $17(24.3)$ & $5(16.1)$ & $12(30.8)$ & 0.127 \\
\hline
\end{tabular}

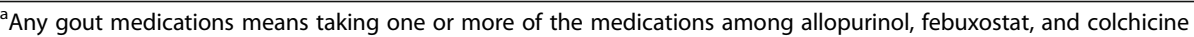
$B M I$, body mass index

Table 2 Clinical characteristics of patients with gout flare during postsurgical period

\begin{tabular}{ll}
\hline Variables & $n=31$ \\
\hline Postoperative period, days & $3.7 \pm 4.9$ \\
Number of involved joint & \\
$\quad$ Monoarticular & $19 / 31(61.3)$ \\
Oligo or polyarticular & $12 / 31(38.7)$ \\
Involved joints at flare & \\
Lower extremity & $26 / 31(83.9)$ \\
Upper extremity & $3 / 31(9.7)$ \\
Both & $2 / 31(6.5)$ \\
Flare site & \\
1st MTP & $6 / 46(13.0)$ \\
Foot except 1st MTP & $12 / 46(26.0)$ \\
Ankle & $10 / 46(21.7)$ \\
Knee & $12 / 46(26.0)$ \\
Elbow & $1 / 46(2.2)$ \\
Wrist & $1 / 46(2.2)$ \\
PIP, MCP & $4 / 46(8.7)$ \\
\hline
\end{tabular}

$M T P$, metatarsophalangeal; $P I P$, proximal interphalangeal joint; $M C P$, metacarpophalangeal that most flares were in the lower extremities, but classic podagra was uncommon [13]. On the other hand, Kang et al. reported that most flares developed in the lower extremities and that the first MTP was the most frequently involved joint, followed by ankle and knee joints [14]. In this study, monoarticular involvement (61.3\%) was more frequent than oligoarticular or polyarticular involvement (38.7\%). A previous study reported that half of the postsurgical gout flares (50.7\%) affected two or more joints [14]. Considering that early episodes of acute gouty arthritis are typically monoarticular, the percentage of oligoarticular or polyarticular involvement seems high in the postsurgical gout flare. Acute flareups are provoked by altering the usual stable microenvironment surrounding the microtophi in the joint space. Destabilization of the microtophi leads to shedding of crystals into the joint space, where they trigger an acute flare [15]. Local factors, such as microtrauma or reduced temperature in distal tissue, are associated preferentially with a gout flare of the big toe [16]. Systemic acidosis caused by surgery changes the $p \mathrm{H}$ of the surrounding synovial fluid and the concentration of the urate [15]. Systemic change during the perioperative period may foster flareups in several joints.

Our study showed that elevated presurgical uric acid, especially greater than $9 \mathrm{mg} / \mathrm{dL}$, is a significant risk factor for postsurgical gout flare. Allopurinol use decreased the risk of gout flare. It is consistent with a previous report that 
Table 3 Comparison of surgery details between patients with gout flare and without gout flare

\begin{tabular}{llll}
\hline & Flare $(n=31)$ & No flare $(n=39)$ & $P$ \\
\hline Operation time (minutes) & $149.5 \pm 87$ & $126.3 \pm 107.3$ & $184.7 \pm 342.9$ \\
Blood loss $(\mathrm{mL})$ & $259.0 \pm 479.9$ & $733.3 \pm 831.6$ & 0.332 \\
Crystalloid $(\mathrm{mL})$ & $894.2 \pm 773.8$ & $254.7 \pm 507.4$ & 0.453 \\
Colloid $(\mathrm{mL})$ & $258.1 \pm 350.7$ & $981.5 \pm 1168.0$ & $4(10.3)$ \\
Fluid intake during operation $(\mathrm{mL})$ & $1152.3 \pm 1039.3$ & & \\
Transfusion, $\mathrm{n}(\%)$ & $3(9.7)$ & $7(17.9)$ \\
Surgical site & & $2(5.1)$ \\
$\quad$ Head and neck & $2(6.5)$ & $0(0.0)$ \\
Intracranial & $0(0.0)$ & $5(12.8)$ \\
Thoracic (heart and lung) & $2(6.5)$ & $3(7.7)$ \\
Gastrointestinal & $9(29.0)$ & $3(7.7)$ \\
Hepatobiliary & $3(9.7)$ & $10(25.6)$ \\
Vascular & $5(16.1)$ & $3(7.7)$ \\
$\quad$ Urinary track, kidney & $7(22.6)$ & $6(15.4)$ \\
Genital & $0(0.0)$ & $9(23.1)$ \\
Musculoskeletal & $3(9.7)$ & $12(38.7)$ & 0.1626 \\
Cancer surgery & & 0.156 \\
\hline
\end{tabular}

elevated presurgical uric acid level $\geq 9 \mathrm{mg} / \mathrm{dL}$ was a risk factor for postsurgical gout flare [14]. Our study suggests that clinicians should be aware that patients with a high uric acid level before surgery may have a postsurgical gout flare. We also found that the amount of uric acid changes between before and after surgery significantly increased the risk of a gout flare. Medications or conditions that rapidly raise or lower uric acid levels in the synovial fluid trigger gout flareups by destabilizing the microtophi. Sudden lowering of serum urate levels is more likely to trigger gout flares than is raising urate levels [15]. Among the 70 patients, 50 (71.4\%) decreased in serum uric acid level after surgery in our study. Starvation, fasting, and fluid administration may be associated with reduced uric acid levels after surgery. Although there was no significant difference in the operation time, blood loss, or fluid intake during the operation, there was a trend that the amounts of blood loss and fluid administered were higher in the flare group than in the no-flare group. Excessive bleeding causes metabolic

Table 4 Univariate analysis for risk factors of postsurgical gout flare

\begin{tabular}{lll}
\hline & OR $(95 \% \mathrm{Cl})$ & $\mathrm{P}$ \\
\hline Presurgical uric acid level & $1.46(1.13-1.88)$ & 0.004 \\
Presurgical uric acid $\geq 9 \mathrm{mg} / \mathrm{dL}$ & $3.77(1.28-11.10)$ & 0.016 \\
Amount of uric acid change & $1.62(1.21-2.18)$ & 0.001 \\
Any gout medications $^{\mathrm{a}}$ & $0.11(0.04-0.32)$ & $<0.001$ \\
Allopurinol use & $0.15(0.05-0.45)$ & 0.001 \\
\hline
\end{tabular}

${ }^{\mathrm{a} A n y}$ gout medications means taking one or more of the medications among allopurinol, febuxostat, and colchicine $O R$, odds ratio; $\mathrm{Cl}$, confidence interval acidosis, which may change the $p \mathrm{H}$ in the joint, resulting in a gout flare. We also found that there was a weak positive correlation between the amount of uric acid changes in the perioperative period and the amount of fluid administered during surgery. Previous studies have shown that reabsorption of sodium and urate accompany at different sites of the nephron $[17,18]$. Basolateral $\mathrm{Na}^{+} / \mathrm{K}^{+}$ATPase generates a $\mathrm{Na}^{+}$gradient that drives some apical $\mathrm{Na}^{+}$-coupled organic anion transporters, which in turn provide the driving force for urate reabsorption [19]. Expansion of intravascular volume or alteration of sodium balance by excess saline infusion during surgery may result in reduced serum uric acid by decreasing urate reabsorption in the proximal tubule.

Although the site of operation was not significantly different between the groups, the gastrointestinal was the most common operation site among the flare group. Kang et al. reported that gastrointestinal surgery was associated with development of gout flare [14]. In gastrointestinal surgery, duration of perioperative fasting tends to take longer than does surgery of other organs, and a high purine diet, such as meat or seafood, might be allowed later than for other types of surgery. The uric acid changes were largest in the gastrointestinal surgery group $(2.9 \pm 2.5 \mathrm{mg} / \mathrm{dL})$ in our study, higher than the mean uric acid changes $(1.9 \pm$ $2.1 \mathrm{mg} / \mathrm{dL}$ ). Patients who underwent gastrointestinal surgery might increase the risk of postsurgical gout flare by means of prolonged fasting and starvation, which in turn rapidly decrease uric acid level.

Treatment of gout flares during postsurgical period, the choice of drug was based on the presence or absence of contraindications and patient's previous experience with 


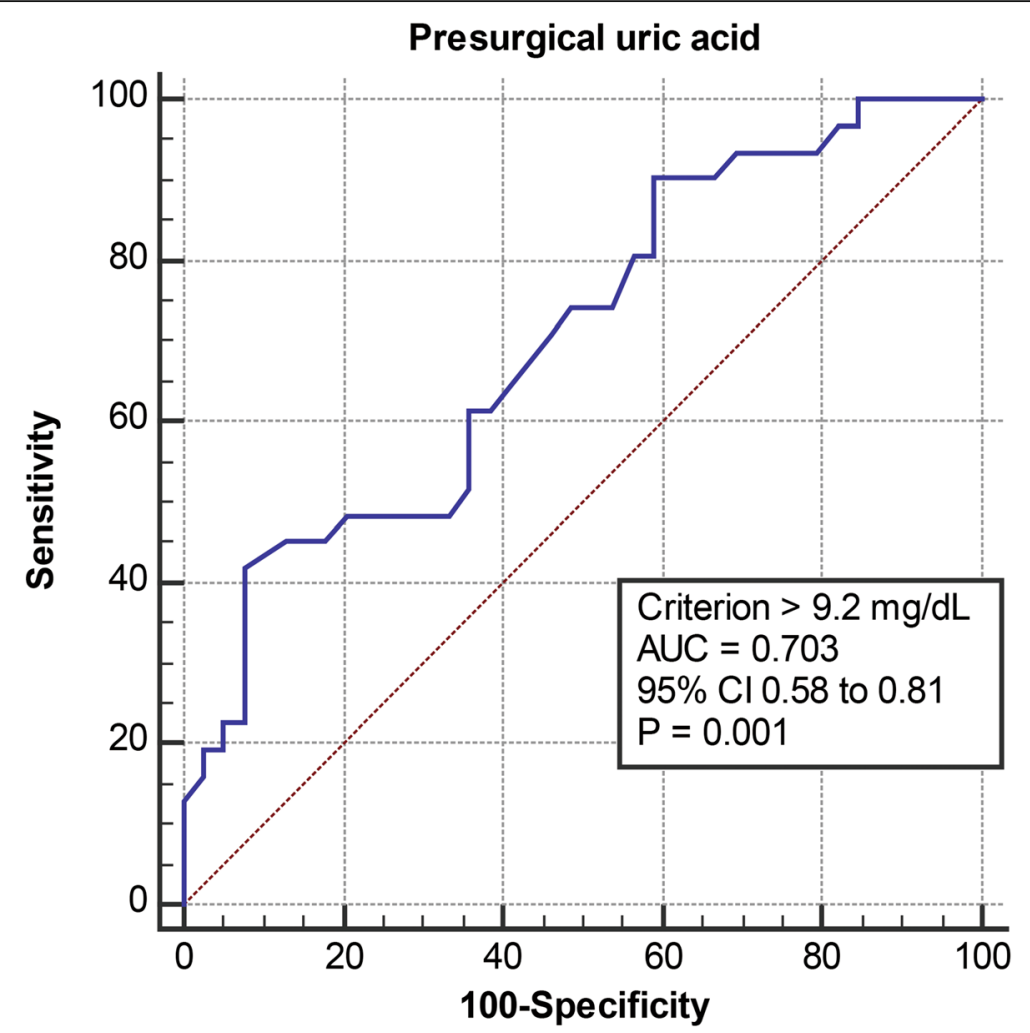

Fig. 1 Presurgical uric acid receiver operating characteristic (ROC) curve for prediction of postsurgical gout flare. Cl, confidence interval; AUC, area under the curve

treatment $[20,21]$. For patients with absence of contraindications, we used non-steroidal anti-inflammatory drugs (NSAIDs) plus proton pump inhibitors if appropriate as a first-line option. In patients with renal impairment, colchicine and NSAIDs were avoided and oral corticosteroid (20 $\mathrm{mg}-30 \mathrm{mg} /$ day of equivalent prednisolone for $3-5$ days) was used. For the nil per os (nothing by mouth) (NPO) patients due to gastrointestinal surgery or medical conditions with involvement of 1-2 joints, intra-articular injection of corticosteroid was used (dose varies by joint size). Intravenous methylprednisolone $(0.5 \mathrm{mg} / \mathrm{kg})$ was also used for NPO patients with polyarticular involvement.

The limitation of this study is its small sample size. We tried to evaluate clinical risk factors, including surgical factors, for postsurgical gout flare. A larger sample size may induce more meaningful results. Other factors that may influence postsurgical gout flares, especially medications such as aspirin, diuretics, and nonsteroidal anti-inflammatory drugs, were not included in the analysis, because it is difficult to quantify the effect of medication on gout flares and the effect is more complicated when several drugs are used at the same time.

\section{Conclusions}

A presurgical high uric acid level, especially greater than $9 \mathrm{mg} / \mathrm{dL}$, and the amount of uric acid changes in the perioperative period were significantly associated with an increased risk of postsurgical gout flare. And taking allopurinol reduced the risk of postsurgical gout flare. Rapidly reduced uric acid in the postsurgical period might be related to fluid administration and fasting during the perioperative period. Our results suggest that adequate uric acid control before surgery could prevent postsurgical gout flares.

\section{Acknowledgements}

Not applicable.

\section{Author's contributions}

HJ conceptualized the study, collected the data, analyzed data, and drafted the manuscript. CHJ conceptualized the study, collected the data, and critically reviewed the article.

\section{Funding}

None.

Availability of data and materials

All data generated or analyzed during this study are included in this published article. The datasets generated and/or analyzed during the current study are not publicly available due to ethics policy of the institutions but are available from the corresponding author on reasonable request.

\section{Ethics approval and consent to participate}

This study was approved by the Institutional Review Board of

Soonchunhyang University Hospital (IRB No. 2018-09-018).

Consent for publication

Not applicable. 


\section{Competing interests}

The authors declare that they have no competing interests.

Received: 26 April 2019 Accepted: 12 July 2019

Published online: 25 July 2019

\section{References}

1. Zhu Y, Pandya BJ, Choi HK. Prevalence of gout and hyperuricemia in the US general population: the National Health and nutrition examination survey 2007-2008. Arthritis Rheum. 2011;63(10):3136-41.

2. Trifiro G, Morabito P, Cavagna L, Ferrajolo C, Pecchioli S, Simonetti M, et al. Epidemiology of gout and hyperuricaemia in Italy during the years 2005-2009: a nationwide population-based study. Ann Rheum Dis. 2013;72(5):694-700.

3. Bursill D, Taylor WJ, Terkeltaub R, Kuwabara M, Merriman TR, Grainger R, et al. Gout, hyperuricemia, and crystal-associated disease network consensus statement regarding labels and definitions for disease elements in gout. Arthritis Care Res (Hoboken). 2019;71(3):427-34.

4. Martinon F, Petrilli V, Mayor A, Tardivel A, Tschopp J. Gout-associated uric acid crystals activate the NALP3 inflammasome. Nature. 2006;440(7081):237-41.

5. Phelps P, DJ MC Jr. Crystal-induced inflammation in canine joints. II. Importance of polymorphonuclear leukocytes. J Exp Med. 1966;124(1):115-26.

6. Guerne PA, Terkeltaub R, Zuraw B, Lotz M. Inflammatory microcrystals stimulate interleukin-6 production and secretion by human monocytes and synoviocytes. Arthritis Rheum. 1989;32(11):1443-52.

7. Terkeltaub R, Zachariae C, Santoro D, Martin J, Peveri P, Matsushima K. Monocyte-derived neutrophil chemotactic factor/interleukin-8 is a potential. mediator of crystal-induced inflammation. Arthritis Rheum. 1991;34(7):894-903.

8. di Giovine FS, Malawista SE, Thornton E, Duff GW. Urate crystals stimulate production of tumor necrosis factor alpha from human blood monocytes and synovial cells. Cytokine mRNA and protein kinetics, and cellular distribution. J Clin Invest. 1991;87(4):1375-81.

9. Singh JA, Reddy SG, Kundukulam J. Risk factors for gout and prevention: a systematic review of the literature. Curr Opin Rheumatol. 2011;23(2):192-202.

10. Friedman JE, Dallal RM, Lord JL. Gouty attacks occur frequently in postoperative gastric bypass patients. Surg Obes Relat Dis. 2008:4(1):11-3.

11. Ogryzlo MA. Hyperuricemia induced by high fat diets and starvation. Arthritis Rheum. 1965;8(5):799-822.

12. Feinstein El, Quion-Verde H, Kaptein EM, Massry SG. Severe hyperuricemia in patients with volume depletion. Am J Nephrol. 1984;4(2):77-80.

13. Craig MH, Poole GV, Hauser CJ. Postsurgical gout. Am Surg. 1995;61(1):56-9.

14. Kang EH, Lee EY, Lee YJ, Song YW, Lee EB. Clinical features and risk factors of postsurgical gout. Ann Rheum Dis. 2008;67(9):1271-5.

15. Edwards NL. Clinical gout. Rheumatology, 6th edition. Philadelphia, PA: Elsevere Mosby; 2015. p. 1569-74.

16. Simkin PA. The pathogenesis of podagra. Ann Intern Med. 1977;86(2):230-3.

17. Ter Maaten JC, Voorburg A, Heine RJ, Ter Wee PM, Donker AJ, Gans RO. Renal handling of urate and sodium during acute physiological hyperinsulinaemia in healthy subjects. Clin Sci (Lond). 1997;92(1):51-8.

18. Quinones Galvan A, Natali A, Baldi S, Frascerra S, Sanna G, Ciociaro D, et al. Effect of insulin on uric acid excretion in humans. Am J Phys. 1995;268(1 Pt 1):E1-5.

19. Bobulescu IA, Moe OW. Renal transport of uric acid: evolving concepts and uncertainties. Adv Chronic Kidney Dis. 2012;19(6):358-71.

20. Richette P, Doherty M, Pascual E, Barskova V, Becce F, Castaneda-Sanabria J, et al. 2016 updated EULAR evidence-based recommendations for the management of gout. Ann Rheum Dis. 2017;76(1):29-42.

21. Khanna D, Khanna PP, Fitzgerald JD, Singh MK, Bae S, Neogi T, et al. 2012 American College of Rheumatology guidelines for management of gout. Part 2: therapy and antiinflammatory prophylaxis of acute gouty arthritis. Arthritis Care Res (Hoboken). 2012;64(10):1447-61.

\section{Publisher's Note}

Springer Nature remains neutral with regard to jurisdictional claims in published maps and institutional affiliations.

Ready to submit your research? Choose BMC and benefit from:

- fast, convenient online submission

- thorough peer review by experienced researchers in your field

- rapid publication on acceptance

- support for research data, including large and complex data types

- gold Open Access which fosters wider collaboration and increased citations

- maximum visibility for your research: over $100 \mathrm{M}$ website views per year

At BMC, research is always in progress.

Learn more biomedcentral.com/submissions 